\title{
Characterization and Molecular Docking of Kaolin Based Cellulosic Film for Extending Ophthalmic Drug Delivery
}

\author{
ARUNIMA PRAMANIK, R. N. SAHOO ${ }^{1}$, A. NANDA ${ }^{1}$, S. K. PRADHAN ${ }^{2}$ AND S. MALLICK* \\ Department of Pharmaceutics, School of Pharmaceutical Sciences, Siksha O Anusandhan (Deemed to be University), ${ }^{1}$ School \\ of Pharmacy and Life Sciences, Centurion University of Technology and Management, 2PG Department of Bioinformatics, \\ Orissa University of Agriculture and Technology, Bhubaneswar 751003, India
}

\section{Pramanik et al.: Molecular Docking of Kaolin Based Cellulosic Film}

\begin{abstract}
Ophthalmic delivery of dexamethasone can control inflammation and also some forms of uveitis. But it is effective therapeutically over a short period of time and frequent instillation is required. Hydroxypropyl methylcellulose matrix films containing dexamethasone were prepared by casting method in presence and absence of particulate kaolin for extending ophthalmic drug delivery. Fourier-transform infrared spectroscopy confirmed the complexation of dexamethasone and kaolin in the film via formation of hydrogen bond and the observed shouldering at $1032 \mathrm{~cm}^{-1}$ increased with corresponding higher amount of kaolin binding. Differential scanning calorimetry thermogram resulted in almost complete amorphization of dexamethasone in the film. X-ray diffractogram demonstrated almost disappearance of kaolinite diffraction and the reduced order of dexamethasone crystal lattice in all the film formulations. Submicrons, tubular and nano-fibrous morphology of the kaolin and drug particles were seen in the scanning electron microscope images of the film. Relatively extended diffusion controlled drug release and ophthalmic permeation behavior were observed with the increase of kaolin loading in the film. Stable complex facilitated the sustained ophthalmic delivery of dexamethasone and prolonged anti-inflammatory activity. Molecular docking study also revealed the complex formation of dexamethasone with kaolin and hydroxypropyl methyl cellulose to understand the fitting and stable configuration of drug-carrier interaction. Kaolin-based hydroxypropyl methyl cellulose hydrogel film containing dexamethasone as a model drug can enhance the corneal residence time for anti-inflammation for an extended period of time.
\end{abstract}

Key words: Particulate kaolin, extended drug delivery, molecular docking, cellulosic ophthalmic film

Topical ophthalmic delivery of corticosteroids can control inflammation and also some forms of uveitis ${ }^{[1,2]}$. Dexamethasone (DXA), a synthetic corticosteroid is widely used as post-operative topical treatment in reducing ocular inflammation ${ }^{[3]}$. DXA may also reduce the breakdown of the blood ocular barrier in proliferative vitreoretinopathy ${ }^{[4]}$. Ophthalmic delivery has limitation associated with less effective drug availability at target site due to the unique anatomy, physiological barrier and the protective mechanism of the eye. DXA is therapeutically effective over a short time period, which leads to frequent instillation of required dose ${ }^{[5]}$. Conventional dosage forms (oral and intravenous administration) have adverse effect like non-specific accumulation of drugs in other organs and complication in drug diffusion through blood retina barrier into the posterior segment ${ }^{[6]}$. Drug delivery to the target site by intravitreal injections may raise difficulties like significant tissue damage, retinal detachment,

*Address for correspondence E-mail: profsmallick@gmail.com bleeding or infection, elevated intraocular pressure and $s o{ }{ }^{[7]}$. Surgically inserted ocular implants deliver drug over long time period but it may be associated with problems of vitreous hemorrhage endophthalmitis and retinal detachment. They may require removal and reinsertion of a new implant after reservoir depletion ${ }^{[8]}$. In situ gel, one of the recent developed preparation exhibited successful result but unclear vision and poor patient compliance were the main reasons of its unacceptability ${ }^{[9]}$. Liposome and nanoparticles may have manufacturing problem associated with poor encapsulation efficiency of active molecules. Both liposome and colloidal dispersions have difficulties of

This is an open access article distributed under the terms of the Creative Commons Attribution-NonCommercial-ShareAlike 3.0 License, which allows others to remix, tweak, and build upon the work non-commercially, as long as the author is credited and the new creations are licensed under the identical terms

Accepted 12 August 2021

Revised 19 July 2021

Received 31 December 2019 Indian J Pharm Sci 2021;83(4):794-807 
the clearance mechanism similar to other foreign bodies upon contact with the ocular surface and are washed out by reflex tearing ${ }^{[10]}$. The other disadvantages of liposome may be due to poor physical and chemical stability ${ }^{[1]}$. Kaolin particle incorporated DXA ophthalmic hydrogel films of hydroxypropyl methylcellulose (HPMC) matrix system ${ }^{[12]}$ may overcome these problems.

Kaolin, a phyllosilicate cationic clay ${ }^{[13]}$ contains a tetrahedral siloxane and an octahedral gibbsite $\left(\mathrm{Al}(\mathrm{OH})_{3}\right)$ sheet. These two layers stack through hydrogen bond to form nanometer thick layers of kaolin. The hydrogen bond between kaolin layers break up when the molecule intercalated into the interlayer space of kaolin layers. It is well accepted in pharmaceutical formulations considering its high specific area, sorption capacity, favorable rheological and swelling properties, and inertness properties. Kaolin can also protect the mucosal membrane by absorbing toxins, bacteria and even viruses ${ }^{[14]}$ when it adheres to the mucosal membrane.

Cellulosic derivatives are the most enthusiastic polymers used in the film preparation ${ }^{[15-17]}$. HPMC, the hydrophilic cellulose ether can be used for the preparation of controlled drug delivery systems ${ }^{[17]}$. The challenge of ophthalmic drug delivery is due to the static and dynamic barriers and efflux pumps which appeared resistance to drug penetration. HPMC, a biocompatible polymer has extensively been used for the topical ophthalmic drug delivery particularly for its biodegradable and bio adhesive property ${ }^{[16,17]}$.

The problem related to release of DXA can be solved with increasing residence time of formulation and better patient compliance. The ocular residence time could be enhanced by sustaining release of DXA from kaolin incorporated HPMC matrix film. Film formulation provided correct self-medication without any wastage of drug concentration ${ }^{[18]}$. Analysis of drug release kinetics requires predicting the molecular mass transport through biological membrane. In past, the mathematical model and semi-empirical equations (first order, Higuchi and Korsmeyer-peppas model) were analyzed for model fitting. Present research work aimed to develop kaolin incorporated DXA ophthalmic film which could extend the release of drug in a controlled manner. This will decrease the instillation frequency of dose and also overcome the additional drawback of eye drop of DXA. The permeation of DXA was discussed by employing mathematical models and statistical moment analysis. A good linear relationship between drug release and corneal permeation has been established. Carrageenan induced paw oedema has been studied by Gupta et al. ${ }^{[19]}$ for anti-inflammatory activity of tenoxicam. We have utilized carrageenan induced rabbit model for conducting conjunctival anti-inflammation ${ }^{[20]}$. Extensive scrutinize of literature revealed that this kind of research work has not been found earlier.

\section{MATERIALS AND METHODS}

DXA acetate was purchased from Sigma Life Science (USA). HPMC K 100 LV (HPMC: $100 \mathrm{mPa} . \mathrm{s}$ ) and HPMC K 100 M (HPMC: 100000 mPa.s) were locally procured from Burgoyne Co. Kaolin and triethanolamine were obtained from Qualikems and Merck Specialities Pvt. Ltd. (Mumbai) respectively. Ethanol (absolute for analysis) was purchased from MERCK (Germany).

\section{Film preparation:}

Kaolin dispersion was prepared in distilled water with continuous stirring for $24 \mathrm{~h}$. After centrifugation at $2500 \mathrm{rpm}$ for a period of $15 \mathrm{~min}$ upper thin nanodispersion layer was utilized for film preparation ${ }^{[21]}$. HPMC K 100 LV $\left(\mathrm{HPMC}_{\mathrm{L}}\right.$ ) and HPMC K $100 \mathrm{M}$ $\left(\mathrm{HPMC}_{\mathrm{H}}\right)$ were swelled separately in ice cooled water for overnight period. Kaolin dispersion in different proportions was added to the polymer dispersion by continuous magnetic stirring for $1 \mathrm{~h}$. DXA and triethanolamine were dissolved in small amount of ethanol and poured in initially prepared polymer dispersion with continuous magnetic stirring for $3 \mathrm{~h}$. The hydrogel film was prepared after casting ${ }^{[15,22,23]}$ the final dispersion in petri plate and drying in an incubator at $45-50^{\circ}$ for $24 \mathrm{~h}$. The prepared films were stored in a wide diameter airtight container. Drug content of the films was estimated from the absorbance in ultra-violet visible spectrophotometer (UV-Vis Spectrophotometer, JASCO V-630) at $240 \mathrm{~nm}$ after dissolving completely in phosphate buffer saline ( $\mathrm{pH}$ 7.4). Mean film thickness was measured using digital micrometer (Mitutoyo, Japan) at six different locations of each film. Films were folded repeatedly as bending back and forth over a curved surface until it ruptures, to check the folding endurance of films. All measurements were performed for triplicate or more.

\section{Opacity of the film:}

A rectangular piece of each film formulation was directly placed in the UV-Vis spectrophotometer cell. The spectrum of each film was recorded in the spectrophotometer (UV-Vis spectrophotometer). The obtained spectrum $(400-800 \mathrm{~nm})$ of each film in 
UV-Vis spectrophotometer has been recorded. All measurements were conducted with air, considered as reference and performed for triplicate. The obtained absorbance at $500 \mathrm{~nm}$ divided by the respective film thickness was used to calculate the opacity of the films ${ }^{[24,25]}$.

\section{Fourier transform infrared (FT-IR) spectroscopy:}

FT-IR analysis performed in JASCO FT-IR-4100 spectra of pure DXA and all formulations to understand possible interaction between components present in film. Samples were placed in FT-IR spectrometer by the using potassium bromide $(\mathrm{KBr})$ pressed-disk method and ratio of sample to $\mathrm{KBr}$ of 1:20. Spectra of FT-IR were obtained in the range of $400-4000 \mathrm{~cm}^{-1}$ and at a resolution of $4 \mathrm{~cm}^{-1}$ as transmission mode by accumulating 80 scans.

\section{Differential scanning calorimetry:}

DXA and film samples were accurately weighed about $6 \mathrm{mg}$ and placed into aluminium crucibles $(40 \mu \mathrm{l})$. Then all samples were scanned over a temperature range from 30 to $280^{\circ}$ at $10^{\circ} \mathrm{min}^{-1}$ heating rate and under dynamic $\mathrm{N}_{2}$ atmosphere in differential scanning calorimeter (Mettler Toledo DSC 1, Switzerland). The calibration of the DSC cell was performed by Indium (Melting point $=156^{\circ} ; \Delta \mathrm{H}_{\text {fus }}=28.54 \mathrm{Jg}^{-1}$ ).

\section{X-ray diffractometry (XRD):}

The XRD analyses of DXA, kaolin, polymer and films were conducted on an x-ray diffractometer (D8 DISCOVER, BRUKER). The data of scattered radiation was captured by an anode detector, operating at a voltage of $40 \mathrm{kV}$ and $15 \mathrm{~mA}$ current. The source of $\mathrm{x}$-ray radiation was anode material $\mathrm{Cu}$, kappa alpha (radiation $1.5406 \AA$ ). XRD pattern of samples were recorded after scanning from 10 to $70^{\circ} 2 \theta$ with scan speed of $1^{\circ} \mathrm{min}^{-1}$.

\section{Scanning electron microscopy (SEM):}

The morphological study of DXA, kaolin, film with kaolin and without kaolin was performed by a scanning electron microscope of model no (JSM-6390, LV, Jeol, Japan) operating at voltage of $5 \mathrm{kV}$. A gold layer was sputter coated on DXA, kaolin and the films by sputter apparatus under argon atmosphere. Then the images were captured at 5000-10 000×magnifications.

\section{Drug release studies:}

The release study of films was conducted in United
States Pharmacopeia (USP) type II dissolution apparatus (Electrolab (TDT06L) USP). Films were cut into small piece and accurately weighed specimens were attached on to glass slide using cyanoacrylate glue ${ }^{[16]}$. Air dried slides containing film were securely placed into the dissolution vessels. The phosphate buffer saline (pH 7.4) was used as dissolution medium to resemble with the physiological and physicochemical factors of eye. The volume of phosphate buffer saline was $200 \mathrm{ml}$ to maintain sink condition ${ }^{[17,26]}$. The dissolution apparatus was operated at $34 \pm 0.5^{\circ}$ with rotation speed of $50 \mathrm{rpm}$ for $6 \mathrm{~h}$. Specified volume of dissolution medium was withdrawn at regular interval of time and replaced by same volume of fresh medium. The filtered samples through $0.45 \mu \mathrm{m}$ membrane filter were analyzed by UV-Vis spectrophotometer at $240 \mathrm{~nm}$. The cumulative percentage release of DXA was calculated and time $v s$. cumulative percentage release was plotted. The experiment was performed in triplicate or more for each sample.

\section{Corneal permeation:}

The corneas utilized for permeation of DXA were derived from goat eye which were collected immediately after sacrifice of goat from slaughter house. From the fresh whole goat eye, the cornea along with 2-4 mm sclera tissue was excised and the washed cornea was tied in the modified Franz diffusion cell of $1.3 \mathrm{~cm}^{2}$ diffusion area. The pH 7.4 phosphate buffer saline had been filled in the receptor chamber and operated at $34 \pm 0.5$ with stirring speed of $50 \mathrm{rpm}$. Films were cut as per size of diffusion area. After placing the films onto the donor chamber, specified samples were taken at suitable time interval for $6 \mathrm{~h}$. The percentage of permeated amount was analyzed by UV spectrophotometer in triplicate or more for each sample. The graph was plotted as time $v s . \mathrm{Q}_{\text {film }}$ (amount of drug permeated in the receptor) and permeability coefficient was calculated from the slop of trend line graph as per the following equation

$\mathrm{P}_{\text {film }}=\mathrm{J}_{\mathrm{s}} / \mathrm{C} \ldots \ldots \ldots \ldots$ (1)

Where $\mathrm{J}_{\mathrm{s}}=$ steady state flux, $\mathrm{C}=\mathrm{drug}$ concentration present in the film $\left(\mathrm{C}=\mathrm{Q}_{\text {film }} / \mathrm{V}_{\text {film }} ; \mathrm{V}_{\text {film }}=\right.$ volume of film $)$ [27].

\section{Anti-inflammatory activity study:}

The anti-inflammatory study was performed using New Zealand albino male rabbits weighing about $2 \mathrm{~kg}$ $(1.8 \text { to } 2.0 \mathrm{~kg})^{[28]}$. Permission was approved from the Siksha OAnusandhan Animal Ethics Committee (Siksha 
O Anusandhan Deemed to be University, Odisha, India, Reg. no. 1171/C/08/CPCSEA) for utilizing animal for this study. Rabbits were acclimatized to the laboratory environment with proper care before proceeding for the study. According to the institutional animal ethics committee, all protocol and guidelines for this study have been followed. Initially, one drop of proparacaine hydrochloride ophthalmic solution USP $0.5 \%$ was applied to the normal rabbit eye for local anesthetization. Carrageenan solution $(200 \mu 1,0.3 \%)$ was injected into the upper palpebral region of the anesthetized eye using micro syringe (Dispo Van $30 \mathrm{G}$, India) attached with 30 gauge needle to induce inflammation. Inflammation was visible to the marked extent after $1 \mathrm{~h}$ of carrageenan injection. A small piece of sterilized film $\left(\mathrm{DH}_{\mathrm{H}} \mathrm{K}_{4}\right)$ was placed in the cul-de-sac of inflammation induced eye and the anti-inflammatory activity of the film has been investigated. The sterilization of the both sides of the films have been carried out by placing those $25 \mathrm{~cm}$ away from UV light and sterilized through UV radiation for 10 min in an UV chamber ${ }^{[29,30]}$.

\section{Statistical analysis:}

The DXA release profile and permeation profile were statistically analyzed by Higuchi and KorsmeyerPeppas $^{[31-34]}$ equation as below

$\mathrm{Q}=\mathrm{K}_{\mathrm{H}} \times \sqrt{\mathrm{t}} \ldots \ldots \ldots \ldots(2)$

$\mathrm{M}_{\mathrm{t}} / \mathrm{M}_{\infty}=\mathrm{K} \times \mathrm{t}^{\mathrm{n}}$

$\mathrm{Q}=$ Amount of DXA release per unit area of film, $\mathrm{K}_{\mathrm{H}}=$ Higuchi release rate constant.

$\mathrm{M}_{\mathrm{t}}=$ Amount of DXA at time $\mathrm{t}, \mathrm{M}_{\infty}=$ maximum amount of DXA available to release, $\mathrm{K}=$ release constant, $\mathrm{n}=$ release exponent.

The dissolution parameters such as rate constant of dissolution, coefficient of determination $\left(\mathrm{r}^{2}\right)$ were calculated from both Higuchi and Korsmeyer-Peppas equation and time required for $50 \%$ release $\left(t_{50}\right)$, dissolution exponent were calculated from KorsmeyerPeppas equation. The permeation parameters such as rate constant of permeation, coefficient of determination $\left(\mathrm{r}^{2}\right)$ were calculated from Higuchi and KorsmeyerPeppas equation, time required for $50 \%$ permeate $\left(t_{50}\right)$, permeation exponent were calculated from KorsmeyerPeppas equation and permeability coefficient calculated from flux of permeation. To understand the differences between the permeation coefficient of formulations, one way analysis of variance (ANOVA) had been used in XLSTAT Software (XLSTAT) ${ }^{[35]}$. The pair wise comparison between formulations was made by two sided Dunnett's test with control (films without kaolin) as $\mathrm{DH}_{\mathrm{L}} \mathrm{K}_{0}$ vs. $\mathrm{DH}_{\mathrm{L}} \mathrm{K}_{1}, \mathrm{DH}_{\mathrm{L}} \mathrm{K}_{0}$ vs. $\mathrm{DH}_{\mathrm{L}} \mathrm{K}_{2}, \mathrm{DH}_{\mathrm{L}} \mathrm{K}_{0}$ vs. $\mathrm{DH}_{\mathrm{L}} \mathrm{K}_{3}, \mathrm{DH}_{\mathrm{L}} \mathrm{K}_{0}$ vs. $\mathrm{DH}_{\mathrm{L}} \mathrm{K}_{4}$ and $\mathrm{DH}_{\mathrm{H}} \mathrm{K}_{0}$ vs. $\mathrm{DH}_{\mathrm{H}} \mathrm{K}_{1}$, $\mathrm{DH}_{\mathrm{H}} \mathrm{K}_{0}$ vs. $\mathrm{DH}_{\mathrm{H}} \mathrm{K}_{2}, \mathrm{DH}_{\mathrm{H}} \mathrm{K}_{0} v s . \mathrm{DH}_{\mathrm{H}} \mathrm{K}_{3}$ and $\mathrm{DH}_{\mathrm{H}} \mathrm{K}_{0}$ vs. $\mathrm{DH}_{\mathrm{H}} \mathrm{K}_{4}$. Permeation profile of all formulations has been correlated with respective drug release profile. The accuracy of relationship was predicted by calculation of coefficient of determination $\left(\mathrm{r}^{2}\right)$ from regression line.

\section{Molecular docking:}

In silico docking study using AutoDock 4 programme was used to predict the binding mode interactions between the molecules ${ }^{[36]}$. The programme uses Lamarckian genetic algorithm, semi empirical free energy force field, grid box based method to allow rapid evaluation of the binding energy and pre-calculating the interaction between every atom type pair at every distance and result clustering procedures. The force field is based on a comprehensive thermodynamic model that allows incorporation of intramolecular energies into the predicted free energy of binding ${ }^{[36]}$. Docking calculations were performed with grid box of size $[(40 \times 40 \times 40)]$ with grid centre to find out the potential binding conformation between DXA, kaolin and HPMC. The list binding energy scored conformations were considered as the best conformation. The detailed procedure of molecular docking (using AutoDock) was adopted from a recent study ${ }^{[37]}$. The molecular visualizations and interaction analysis was performed using Discovery studio visualizer (Acceleris Inc.). The three dimensional (3D) structure file of DXA was downloaded from DrugBank (ID:DB01234) ${ }^{[38]}$ as protein data bank (PDB) format. The 3D structures of kaolin and HPMC were drawn by using marvin sketch ${ }^{[28]}$ and save as PDB extension files. The non-bonded H-atoms were merged, Kollman united atom type charges and solvation parameters were added. The protein data bank, partial charge and atom type (PDBQT) files of DXA, HPMC and kaolin were prepared with the help of AutoDock tools programme ${ }^{[39]}$. The DXA steroidal anti-inflammatory drug was taken as a receptor to identify its binding affinity against the ligand kaolin as well as HPMC, a water soluble polymer used for sustained ophthalmic drug release. Interactions DXA-kaolin complex with HPMC were evaluated using molecular docking. The docking complex stability was measured on the basis of binding constant and interaction energy ${ }^{[40]}$. 


\section{RESULTS AND DISCUSSION}

The prepared film formulations were appeared smooth texture in surface and uniform drug content. Ocular film formulation for placing in the cul-de-sac should be uniform without visible cracks, smooth texture and unblemished for better patient comfort. The film formulation and their properties are tabulated in Table 1. The thickness of $\mathrm{HPMC}_{\mathrm{H}}$ based films was comparatively higher than that of $\mathrm{HPMC}_{\mathrm{L}}$ films because of increased viscosity of the polymer. Mean thickness was increased from 94 to 97 and 107 to $116(\mu \mathrm{m})$ with the increase of kaolin content of $\mathrm{HPMC}_{\mathrm{L}}$ and $\mathrm{HPMC}_{\mathrm{H}}$ based film respectively. External eye is more tolerant to isotonicity variation and is particularly important in intra ocular solution. Usually eye can tolerate solution equivalent to a range of $0.5-1.8 \%$ sodium chloride solution. Superior flexibility as indicated by adequate folding endurance $(>200)$ can help in administering the films without breakage and could meet good patient compliance. Opacity of the films varied 1.41 to 2.36 (Table 1) and the transparency of film has been shown in fig. 1A. The visual transparency of the films did not significantly affect with increasing kaolin content.

In order to analyze the chemical constituent of pharmaceuticals and their interaction, FT-IR is the most suitable and widely used technique ${ }^{[41,42]}$. The drugexcipient interaction nature proved from the several changes in IR spectra. The distinct evidence of drugexcipient interaction nature in IR spectra are appearance of new and disappearance of exiting absorption bands, broadening of bands and alteration in intensity. IR spectra of pure DXA, kaolin and formulations have been showed in fig. 1B. DXA IR spectrum showed characteristic absorption peak at $3000-2800 \mathrm{~cm}^{-1}$, $885 \mathrm{~cm}^{-1}, 1718 \mathrm{~cm}^{-1}, 1665 \mathrm{~cm}^{-1}$ and $1621 \mathrm{~cm}^{-1}$, assigned to $\mathrm{CH}_{2}$ group, axial deformation of $\mathrm{C}-\mathrm{F}$ group, carbonyl group $(\mathrm{C}=\mathrm{O})$ of aliphatic ester and ketone ${ }^{[18]}$ and $\mathrm{C}=\mathrm{C}$ group respectively ${ }^{[43]}$. In spectrum of pure kaolin, an intense absorption peak observed at $1032 \mathrm{~cm}^{-1}$ assigned to Si-O stretching in kaolin ${ }^{[44]}$. As per position of hydroxyl group in kaolin, it contains outer hydroxyl group $(\mathrm{OuOH})$ (positioned in the upper unshared plan) and inner hydroxyl group ( $\mathrm{InOH})$ (positioned in lower unshared plan of octahedral sheet). The absorption band at $3693,3669,3649 \mathrm{~cm}^{-1}$ and at $3619 \mathrm{~cm}^{-1}$ presents in spectrum of kaolin assigned for the stretching of $\mathrm{OuOH}$ and stretching of $\mathrm{InOH}$ in aluminum hydroxide $(\mathrm{Al}-\mathrm{OH})^{[45]}$. However, the positions of Al-OH group of kaolin $\left(3693 \mathrm{~cm}^{-1}\right)$ and carbonyl group of DXA $\left(1665 \mathrm{~cm}^{-1}\right)$ have been shifted in IR spectrum of films containing kaolin. FTIR spectrum of films exhibited the

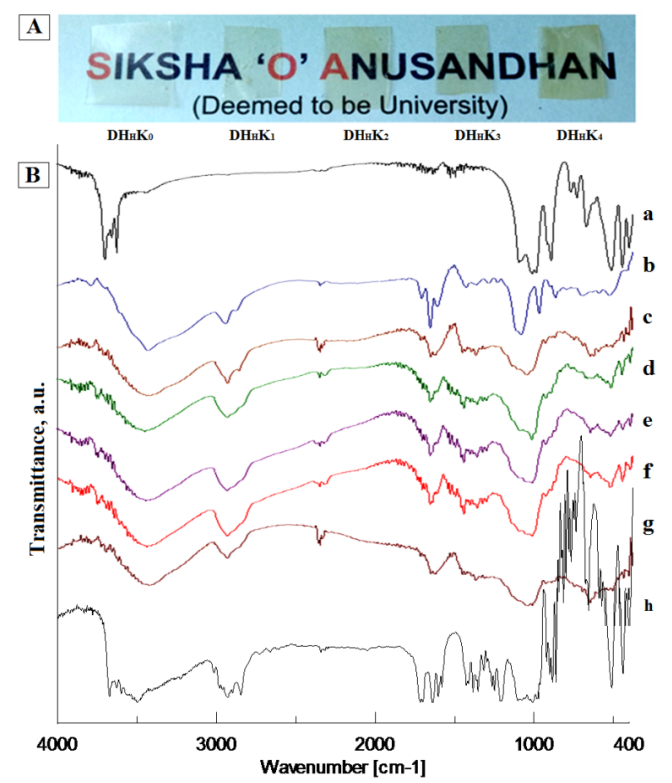

Fig. 1: (A) Visual transparency of the films $\left(\mathrm{DH}_{\mathrm{H}} \mathrm{K}_{\mathbf{0}}, \mathrm{DH}_{\mathrm{H}} \mathrm{K}_{1}\right.$, $\mathrm{DH}_{\mathrm{H}} \mathrm{K}_{2}, \mathrm{DH}_{\mathrm{H}} \mathrm{K}_{3}$ and $\mathrm{DH}_{\mathrm{H}} \mathrm{K}_{4}$ ). Increasing kaolin content has slightly increased opacity but did not affect transparency adequately; (B) FTIR spectra of kaolin, DXA and films (a-kaolin, b-DXA, c-DH $\mathrm{K}_{0}, \mathrm{~d}-\mathrm{DH} \mathrm{H}_{\mathrm{H}}, \mathrm{e}-\mathrm{DH} \mathrm{H}_{\mathrm{H}}, \mathbf{f}-\mathrm{DH} \mathrm{H}_{\mathrm{H}} \mathrm{K}_{3}$, g-DH $\mathrm{H}_{4}$, h-physical mixture)

\section{TABLE 1: FORMULATION OF KAOLIN-BASED HPMC FILM ${ }^{\mathrm{a}}$ FOR OPHTHALMIC DRUG DELIVERY}

\begin{tabular}{|c|c|c|c|c|c|}
\hline Film code & Polymer & DXA/kaolin ratio & Assay (\%) & $\begin{array}{c}\text { Thickness, } \\
\text { mean } \pm S D, n=6(\mu \mathrm{m})\end{array}$ & $\begin{array}{l}\text { Opacity } \\
\left(\mathrm{UA} \mu \mathrm{m}^{-1}\right)\end{array}$ \\
\hline$\overline{\mathrm{DH}_{\mathrm{L}} \mathrm{K}_{0}}$ & $\mathrm{HPMC}_{\mathrm{L}}$ & Kaolin-nil & $9.973 \pm 0.059$ & $94 \pm 0.02$ & $1.41 \pm 0.02$ \\
\hline $\mathrm{DH}_{\mathrm{L}} \mathrm{K}_{1}$ & $\mathrm{HPMC}_{\mathrm{L}}$ & $1: 0.25$ & $9.489 \pm 0.098$ & $94 \pm 0.02$ & $1.62 \pm 0.03$ \\
\hline $\mathrm{DH}_{\mathrm{L}} \mathrm{K}_{2}$ & $\mathrm{HPMC}_{\mathrm{L}}$ & $1: 0.50$ & $9.345 \pm 0.069$ & $95 \pm 0.02$ & $1.77 \pm 0.01$ \\
\hline $\mathrm{DH}_{\mathrm{L}} \mathrm{K}_{3}$ & $\mathrm{HPMC}_{\mathrm{L}}$ & $1: 0.75$ & $9.092 \pm 0.092$ & $96 \pm 0.03$ & $1.94 \pm 0.04$ \\
\hline $\mathrm{DH}_{\mathrm{L}} \mathrm{K}_{4}^{3}$ & $\mathrm{HPMC}_{\mathrm{L}}^{\mathrm{L}}$ & $1: 1$ & $8.728 \pm 0.086$ & $97 \pm 0.03$ & $2.33 \pm 0.05$ \\
\hline $\mathrm{DH}_{\mathrm{H}} \mathrm{K}_{0}^{4}$ & $\mathrm{HPMC}_{\mathrm{H}}^{\mathrm{L}}$ & Kaolin-nil & $9.877 \pm 0.091$ & $107 \pm 0.01$ & $1.42 \pm 0.04$ \\
\hline $\mathrm{DH}_{\mathrm{H}} \mathrm{K}_{1}$ & $\mathrm{HPMC}_{\mathrm{H}}$ & $1: 0.25$ & $9.551 \pm 0.088$ & $108 \pm 0.02$ & $1.64 \pm 0.01$ \\
\hline $\mathrm{DH}_{\mathrm{H}} \mathrm{K}_{2}$ & $\mathrm{HPMC}_{\mathrm{H}}$ & $1: 0.50$ & $9.409 \pm 0.102$ & $109 \pm 0.01$ & $1.75 \pm 0.05$ \\
\hline $\mathrm{DH}_{\mathrm{H}} \mathrm{K}_{3}$ & $\mathrm{HPMC}_{\mathrm{H}}$ & $1: 0.75$ & $9.019 \pm 0.096$ & $115 \pm 0.01$ & $1.96 \pm 0.03$ \\
\hline $\mathrm{DH}_{\mathrm{H}} \mathrm{K}_{4}$ & $\mathrm{HPMC}_{\mathrm{H}}$ & $1: 1$ & $8.992 \pm 0.095$ & $116 \pm 0.02$ & $2.36 \pm 0.06$ \\
\hline
\end{tabular}

Note: aln film casting triethamolamine used $15 \%$ and solvent used ethanol-water; ${ }^{\text {HPMC }}$ and HPMCH are the HPMC K 100 LV and HPMC K $100 \mathrm{M}$ respectively. Folding endurance has been shown $>200$ (count) 
evidence of a shift of the Al-OH group position from $3693 \mathrm{~cm}^{-1}$ to $3444 \mathrm{~cm}^{-1}$ and the carbonyl group position from $1665 \mathrm{~cm}^{-1}$ to $1660 \mathrm{~cm}^{-1}$. The spectrum of films showed a shouldering of peak at $1032 \mathrm{~cm}^{-1}$. The absorption band shifting can be explained by the formation of hydrogen bond between DXA and kaolin. These spectral shifts in films confirmed that the complexation between DXA and kaolin due to formation of hydrogen bond. The observed shouldering at $1032 \mathrm{~cm}^{-1}$ occurred with the binding of kaolin amount in films. This shouldering increased with corresponding higher amount of kaolin binding.

The thermal properties of drug and films such as melting point, crystallinity and degradation of drug have been established through analyzing the thermograms. DSC thermogram of DXA and the films with and without kaolin of both the HPMC grades $\left(\mathrm{HPMC}_{\mathrm{L}}\right.$ and $\mathrm{HPMC}_{\mathrm{H}}$ ) are shown in fig. 2. The onset of endotherm and melting peak were found at 225.53 and $229.50^{\circ}$ respectively in the thermogram of $\mathrm{DXA}^{[43]}$. The initial broad endothermic effect was observed at $60-110^{\circ}$ in the thermogram of HPMC. The thermogram of physical mixture showed low intensity peak of DXA for melting point than pure DXA. The sharp endothermic peak at $229.50^{\circ}$ was disappeared in the thermogram of films. The characteristic sharp endothermic melting peak proved crystallinity of DXA. The observed an initial broad endothermic effect probably due to the evaporation of moisture present in the polymer ${ }^{[46,47]}$. The low intense endothermic peak of DXA in physical mixture confirmed the crystallization of DXA in physical mixture. The absence of sharp endothermic peak near the melting peak of crystalline DXA indicated amorphization of drug within the film.

$\mathrm{X}$ ray diffraction was performed to investigate the intercalation/exfoliation status of kaolin and also the crystallinity of the DXA in the film. X ray diffractogram of DXA and the films with and without kaolin of both the HPMC grades $\left(\mathrm{HPMC}_{\mathrm{L}}\right.$ and $\left.\mathrm{HPMC}_{\mathrm{H}}\right)$ are presented in fig. 3. Pattern of DXA exhibited the diffraction peak at $14.23,15.24,15.74,16.98,18.61$ and $22.83^{\circ}$ (20) corresponding to interplanar distances of 6.22 , 5.81, 5.62, 5.22, 4.76 and $3.89 \AA$ respectively. The characteristic intense peaks of kaolin were observed at $12.31,24.91$ and $31.77^{[48]}$ corresponding to the interplanar distances of 7.18, 3.57 and 2.81 respectively for kaolinite. X ray diffractogram of DXA and kaolin reflected the sharp peaks associated with their respective crystalline nature. The diffractogram of HPMC did not show any sharp peak rather a halo patterned broad features in the range of $\sim 7$ to 32 . The halo pattern in the diffractogram of HPMC exhibited due to its amorphous nature ${ }^{[49]}$. The characteristic sharp peak of DXA was disappeared in the diffractogram of the films. $X$ ray diffractogram of physical mixture of all ingredients showed the sharp peak of DXA, kaolin with respective low intensity. Triethanolamine, the plasticizer in combination with HPMC inhibited the development of drug crystal in the films ${ }^{[50]}$. The transformation of crystalline state of DXA to micro-crystalline and nanocrystalline form or amorphous state has been confirmed by the disappearance of sharp peak of DXA. The

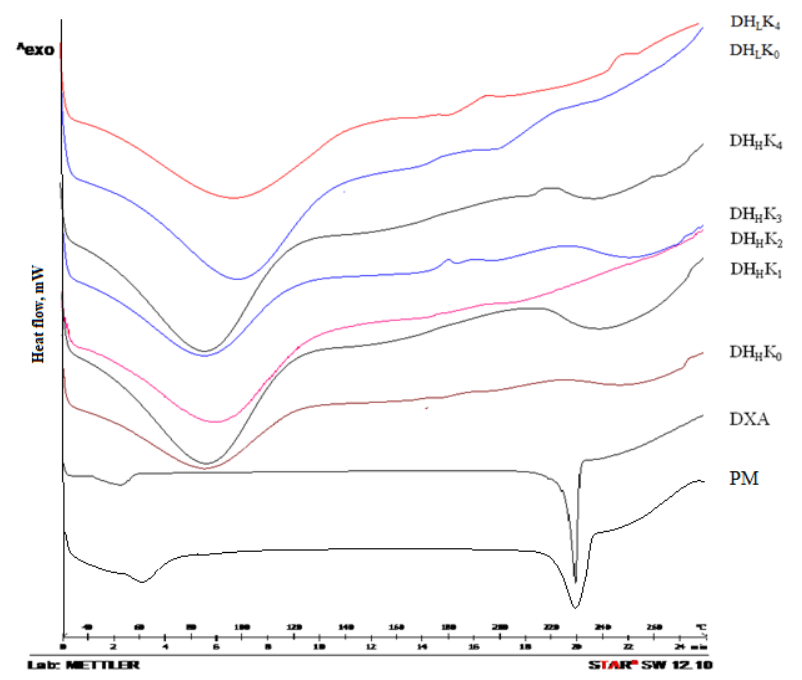

Fig. 2: DSC thermogram of DXA, physical mixture, all films $\left(D H_{H} K_{0}, D H_{H} K_{1}, D H_{H} K_{2}, D H_{H} K_{3}, D H_{H} K_{4}, D H_{L} K_{0}\right.$ and DH $\left.K_{4}\right)$

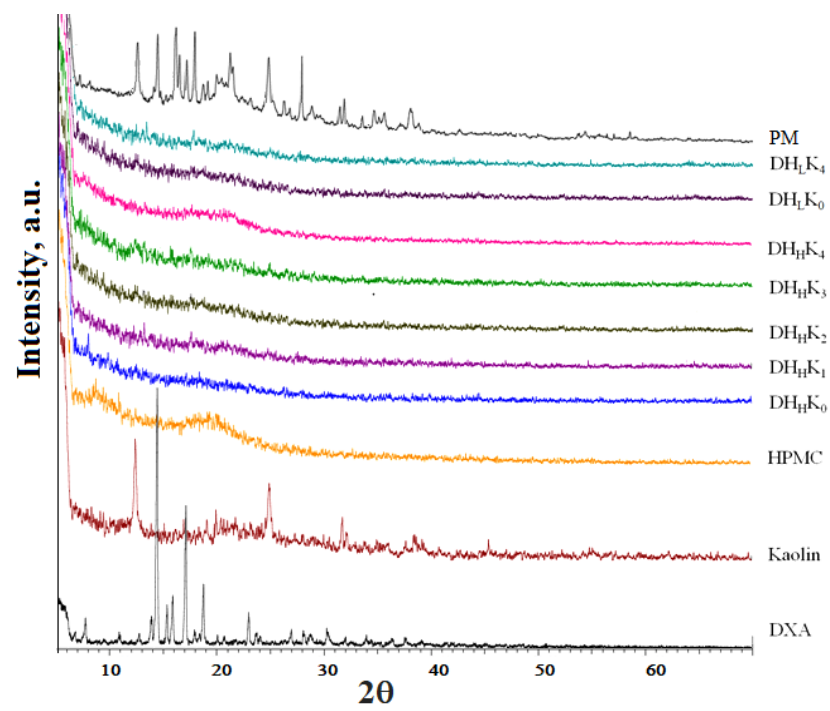

Fig. 3: XRD pattern of kaolin and DXA are showing characteristic diffraction peaks associated with the crystalline materials. The absence of diffraction peaks is seen in the XRD of $\mathrm{HPMC}_{\mathrm{H}}$ due to amorphous nature. Narrow peaks associated with the crystalline materials are almost absent in the XRD of films with and without kaolin $\left(\mathrm{DH}_{\mathrm{H}} \mathrm{K}_{0}, \mathrm{DH}_{\mathrm{H}} \mathrm{K}_{1}, \mathrm{DH}_{\mathrm{H}} \mathrm{K}_{2}, \mathrm{DH}_{\mathrm{H}} \mathrm{K}_{3}\right.$, $\mathrm{DH}_{\mathrm{H}} \mathrm{K}_{4}, \mathrm{DH}_{\mathrm{L}} \mathrm{K}_{0}$ and $\left.\mathrm{DH}_{\mathrm{L}} \mathrm{K}_{4}\right)$ 
presence of DXA crystal in physical mixture has been proved from the X-ray diffractogram. Diffractogram of kaolinite almost disappeared also in all the film formulations probably due to the transformation of kaolinite to amorphous metakaolinite ${ }^{[51]}$.

The SEM photographs represent the surface morphology of the crystalline DXA, kaolin and films.

The SEM images of DXA and film formulations are presented in fig. 4A-fig. 4F. DXA crystals are discrete and of geometric plate shape (fig. 4A). Submicron and nanosized kaolin particles are observed in fig. 4B. Submicrons, tubular and nano-fibrous morphology of the particles are seen in the film micrographs (fig. 4Cfig. $4 \mathrm{~F})$. Relatively thick fibrous $\left(\mathrm{DH}_{\mathrm{L}} \mathrm{K}_{0}\right.$ and $\mathrm{DH}_{\mathrm{H}} \mathrm{K}_{0}$ in fig. $4 \mathrm{C}$ and fig. $4 \mathrm{E}$ respectively) and thin tubular $\left(\mathrm{DH}_{\mathrm{L}} \mathrm{K}_{4}\right.$ and $\mathrm{DH}_{\mathrm{H}} \mathrm{K}_{4}$ in fig. $4 \mathrm{D}$ and fig. $4 \mathrm{~F}$ respectively)
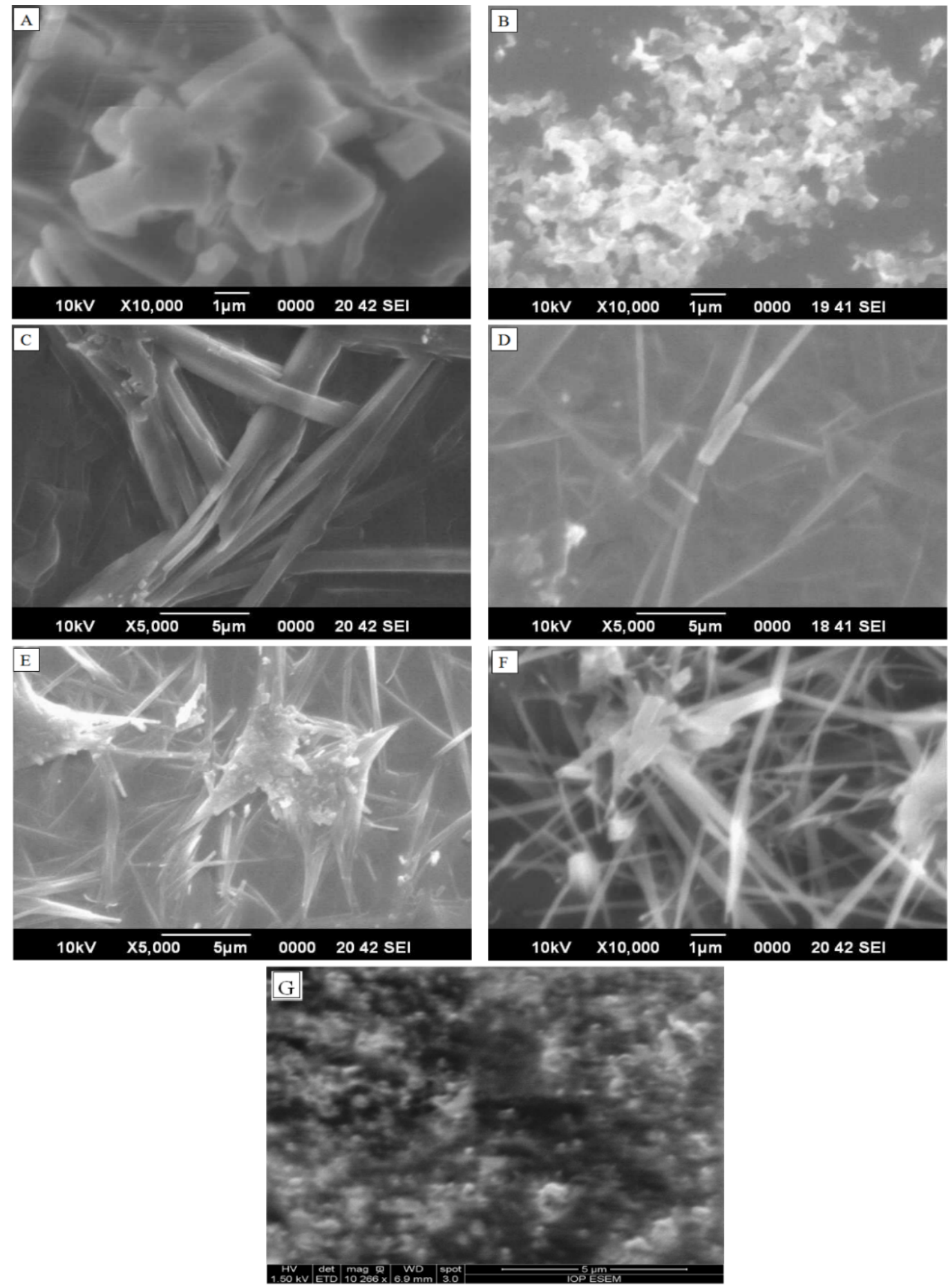

Fig. 4: SEM photograph of (A) DXA; (B) Kaolin represents the surface morphology of the crystalline drug and kaolin respectively. DXA was converted to submicron and nanomicron fiber like structure in the HPMC matrix of the film formulation; (C) DH $\mathrm{K}_{\mathbf{0}}$; (D) $\mathrm{DH}_{\mathrm{L}} \mathrm{K}_{4} ;(\mathrm{E}) \mathrm{DH}_{\mathrm{H}} \mathrm{K}_{0} ;(\mathrm{F}) \mathrm{DH}_{\mathrm{H}} \mathrm{K}_{4}$. Thinner tubular appearance was observed in the presence of kaolin (D, F) when compared with the absence of kaolin (C, E); (G) Film contain kaolin but without DXA 
morphology are due to absence and presence of kaolin in the film. The plate like geometric shape of DXA was converted to submicron and nanomicron fiber like structure in the HPMC matrix in the absence of kaolin whereas, comparatively thinner tubular appearance was observed in the presence of kaolin. The changes of surface morphology of film in presence of DXA and kaolin, verified from SEM photographs. Submicron and nanosized kaolin particles are observed almost like pseudo hexagonal crystals of kaolinite type as reported in the literature (fig. 4B) ${ }^{[52]}$. This special tubular kaolinite appearance might be due to intercalation with DXA. The special nanotubular kaolinite behavior was found in the literature when kaolinite intercalated with potassium acetate ${ }^{[53]}$. The SEM micrograph of films confirmed the disappearance of DXA geometric plate structure probably due to amorphization of drug. In presence of triethanolamine as the plasticizer in HPMC matrix the drug crystal growth has been inhibited significantly due to interfacial adhesion between drug and polymer phase. Also HPMC has crystal habit modifying property and crystal growth inhibiting property ${ }^{[29]}$.

All formulations were subjected to drug release for $6 \mathrm{~h}$ in phosphate buffer saline ( $\mathrm{pH}$ 7.4). DXA release from HPMC matrix films without and with kaolin is shown in fig. 5A, fig. 5B (A: $\mathrm{HPMC}_{\mathrm{L}}$ and $\mathrm{B}: \mathrm{HPMC}_{\mathrm{H}}$ ). Film showed almost complete release after 150 and 240 min in absence of kaolin from the film $\mathrm{DH}_{\mathrm{L}} \mathrm{K}_{0}$ $(98 \%)$ and $\mathrm{DH}_{\mathrm{H}} \mathrm{K}_{0}(93 \%)$ respectively. Whereas, the release extended up to $6 \mathrm{~h}$ (up to $98 \%$ ) and more (up to $88 \%$ by $6 \mathrm{~h}$ ) in presence of kaolin from $\mathrm{HPMC}_{\mathrm{L}}$ and $\mathrm{HPMC}_{\mathrm{H}}$ matrix respectively. The order of DXA release from $\mathrm{HPMC}_{\mathrm{L}}$ and $\mathrm{HPMC}_{\mathrm{H}}$ matrices is as follows: $\mathrm{DH}_{\mathrm{L}} \mathrm{K}_{0}<\mathrm{DH}_{\mathrm{L}} \mathrm{K}_{1}<\mathrm{DH}_{\mathrm{L}} \mathrm{K}_{2}<\mathrm{DH}_{\mathrm{L}} \mathrm{K}_{3}<\mathrm{DH}_{\mathrm{L}} \mathrm{K}_{4}$ and
$\mathrm{DH}_{\mathrm{H}} \mathrm{K}_{0}<\mathrm{DH}_{\mathrm{H}} \mathrm{K}_{1}<\mathrm{DH}_{\mathrm{H}} \mathrm{K}_{2}<\mathrm{DH}_{\mathrm{H}} \mathrm{K}_{3}<\mathrm{DH}_{\mathrm{H}} \mathrm{K}_{4}$ respectively. Faster release was observed with $\mathrm{HPMC}_{\mathrm{L}}$ compared to $\mathrm{HPMC}_{\mathrm{H}}$ films and because of less viscosity $\mathrm{HPMC}_{\mathrm{L}}$ film eroded faster compared to $\mathrm{HPMC}_{\mathrm{H}}$ film. A gradual increase in kaolin loading gradually more sustained drug release with consequent less erosion of the films.

Higuchi and Korsmeyer-Peppas model was utilized for evaluating the dissolution kinetics. The parameters such as Higuchi release rate constant $\left(\mathrm{K}_{\mathrm{r}}\right)$, coefficient of determination $\left(\mathrm{r}^{2}\right)$, release exponent $(\mathrm{n})$ and time required for $50 \%$ dissolution $\left(\mathrm{t}_{50}\right)$ are depicted in the Table 2. The release mechanism could be described by $n$ value of all the formulations (0.100-0.373). The calculated $n$ value appeared less than 0.5 of all the formulations. The $\mathrm{n}$ value of Peppas model suggested that the release mechanism was predominantly diffusion controlled $^{[54-56]}$. Films containing kaolin showed higher $\mathrm{t}_{50}$ value than films without kaolin. Increased $t_{50}$ value was also observed from $\mathrm{HPMC}_{\mathrm{H}}$ matrix compared to $\mathrm{HPMC}_{\mathrm{L}}$ matrix film.

Drug release of film with increasing kaolin content demonstrated gradual prolonged release. The availability of free DXA molecules was restricted with increased content of kaolin and decreased the release rate of DXA in sustained manner. Some drug molecules have been adsorbed on the available surface of kaolin particles present in the film formulation and might have extended the release of DXA. DXA adsorption was occurred by the cation exchange on the edge of kaolin and hydrogen bonding as a function of the hydroxyl groups which considered as major reactive part positioned at surface edge of the plane. Relatively faster release behavior was observed from $\mathrm{HPMC}_{\mathrm{L}}$ matrix formulation compared to $\mathrm{HPMC}_{\mathrm{H}}$ formulation. The higher viscosity of $\mathrm{HPMC}_{\mathrm{H}}$ provided reduced
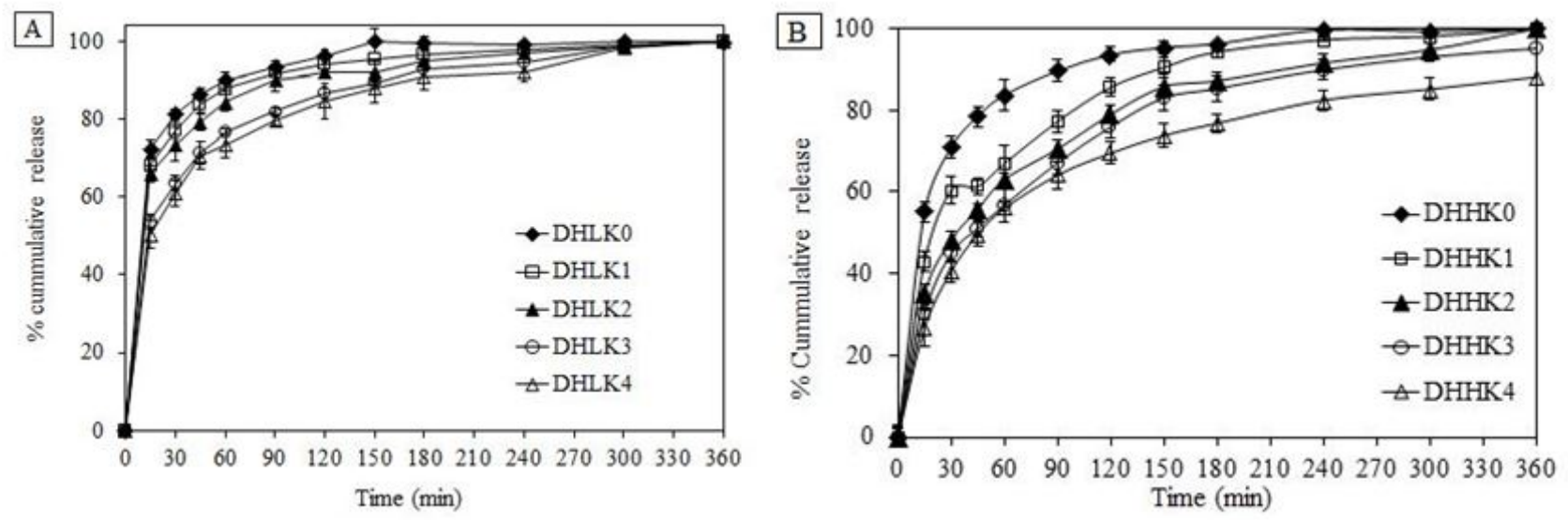

Fig. 5: Cumulative percentage drug release profile from films prepared with (A) $H_{P M C}$ and (B) $\mathrm{HPMC}_{\mathrm{H}}$. $A$ faster release was observed with $\mathrm{HPMC}_{\mathrm{L}}$ compared to $\mathrm{HPMC}_{\mathrm{H}}$ films. A gradual increase in kaolin loading gradually more sustained drug release from all the films 
effective molecular diffusion area which reflected in more tortuous and resistant barrier to diffusion. This release mechanism of high viscosity polymer resulted in slower and sustained release of DXA from $\mathrm{HPMC}_{\mathrm{H}}$ film compared to lower viscosity $\mathrm{HPMC}_{\mathrm{L}}$ film. Correspondingly increased $t_{50}$ value with the respective increased kaolin content supported that the release has been extended more with increased kaolin content in films.

Corneal permeation study was carried out for $6 \mathrm{~h}$ to understand the transportation of drug through excised corneal mucosa. Ex vivo permeation per unit area $v s$. time profile of all the film formulations is illustrated in fig. 6A and fig. 6B (A: $\mathrm{HPMC}_{\mathrm{L}}$ and B: $\left.\mathrm{HPMC}_{\mathrm{H}}\right)$. Delayed permeation was observed with $\mathrm{HPMC}_{\mathrm{H}}$ (57.75 to $37.67 \%$ ) compared to $\mathrm{HPMC}_{\mathrm{L}}$ matrix (88.93 to $64.49 \%$ ) after $6 \mathrm{~h}$. Drug permeation has been gradually more extended 82.91 to $64.49 \%$ and 56.23 to $37.67 \%$ with the increase of kaolin loading from $1: 0.25$ to $1: 1$ (drug/kaolin ratio) in the $\mathrm{HPMC}_{\mathrm{L}}$ and $\mathrm{HPMC}_{\mathrm{H}}$ matrix respectively at $6 \mathrm{~h}$. The permeation rate was decreased with increased kaolin content also in the film correspondingly.
Kinetics of permeation was evaluated using Higuchi and Korsmeyer-Peppas model. Higuchi permeation rate constant $\left(\mathrm{K}_{\mathrm{p}}\right)$, coefficient of determination $\left(\mathrm{r}^{2}\right)$, permeation exponent (n) and time required for $50 \%$ permeation $\left(\mathrm{t}_{50}\right)$ are reported in the Table $2 . \mathrm{DH}_{\mathrm{H}} \mathrm{K}_{2}$, $\mathrm{DH}_{\mathrm{H}} \mathrm{K}_{3}$ and $\mathrm{DH}_{\mathrm{H}} \mathrm{K}_{4}$ films showed $\mathrm{t}_{50}$ value (345.3, 353.9 and 356.7 min respectively) significantly higher compared to other formulations $\mathrm{DH}_{\mathrm{L}} \mathrm{K}_{0}, \mathrm{DH}_{\mathrm{L}} \mathrm{K}_{1}, \mathrm{DH}_{\mathrm{L}} \mathrm{K}_{2}$, $\mathrm{DH}_{\mathrm{L}} \mathrm{K}_{3}, \mathrm{DH}_{\mathrm{L}} \mathrm{K}_{4}, \mathrm{DH}_{\mathrm{H}} \mathrm{K}_{0}, \mathrm{DH}_{\mathrm{H}} \mathrm{K}_{1}(66.3,87.5,112.7$, 137.4, 154.7, 184.9 and $203.2 \mathrm{~min}$ ). All formulations of $\mathrm{HPMC}_{\mathrm{L}}$ and $\mathrm{HPMC}_{\mathrm{H}}$ matrix extended permeation up to $70 \%$ except $\mathrm{DH}_{\mathrm{H}} \mathrm{K}_{3}$ and $\mathrm{DH}_{\mathrm{H}} \mathrm{K}_{4}$ films (less than $50 \%$ ).

The changes in permeation coefficient $\left(\mathrm{P}_{\text {film }}\right)$ and flux $\left(\mathrm{J}_{\mathrm{s}}\right)$ as a function of kaolin content and polymer matrices $\left(\mathrm{HPMC}_{\mathrm{L}}\right.$ and $\mathrm{HPMC}_{\mathrm{H}}$ ) in the films are shown in fig. 7A, fig. 7B. Both $\mathrm{P}_{\text {film }}$ and $\mathrm{J}_{\mathrm{s}}$ demonstrated decreased value with the increased kaolin content and higher value in absence of kaolin in the film. Dunnett's test analysis (Table 3) demonstrated the confirmation of significant difference of permeation coefficient between control film without kaolin and film containing kaolin pair wise as: $\mathrm{DH}_{\mathrm{L}} \mathrm{K}_{0} v s . \mathrm{DH}_{\mathrm{L}} \mathrm{K}_{1}, \mathrm{DH}_{\mathrm{L}} \mathrm{K}_{0} v s . \mathrm{DH}_{\mathrm{L}} \mathrm{K}_{2}, \mathrm{DH}_{\mathrm{L}} \mathrm{K}_{0} v s$. $\mathrm{DH}_{\mathrm{L}} \mathrm{K}_{3}$ and $\mathrm{DH}_{\mathrm{L}} \mathrm{K}_{0}$ vs. $\mathrm{DH}_{\mathrm{L}} \mathrm{K}_{4}$ and $\mathrm{DH}_{\mathrm{H}} \mathrm{K}_{0}$ vs. $\mathrm{DH}_{\mathrm{H}} \mathrm{K}_{1}$,

TABLE 2: KINETICS OF DRUG RELEASE AND CORNEAL PERMEATION

\begin{tabular}{|c|c|c|c|c|c|c|c|c|c|c|}
\hline \multirow{3}{*}{$\begin{array}{l}\text { Formulation } \\
\text { code }\end{array}$} & \multicolumn{5}{|c|}{ In vitro drug release } & \multicolumn{5}{|c|}{ Ex vivo corneal permeation } \\
\hline & \multicolumn{2}{|c|}{ Higuchi } & \multicolumn{3}{|c|}{ Peppas } & \multicolumn{2}{|c|}{ Higuchi } & \multicolumn{3}{|c|}{ Peppas } \\
\hline & $\mathrm{K}_{\mathrm{r}}\left(\% \min ^{-1 / 2}\right)$ & $r^{2}$ & $\mathbf{n}$ & $t_{50}(\min )$ & $r^{2}$ & $\mathrm{~K}_{\mathrm{p}}\left(\% \mathrm{~min}^{-1 / 2}\right)$ & $r^{2}$ & $\mathrm{n}$ & $t_{50}(\min )$ & $r^{2}$ \\
\hline$\overline{\mathrm{DH}_{\mathrm{L}} \mathrm{K}_{0}}$ & 2.74 & 0.929 & 0.10 & 0.23 & 0.908 & 4.135 & 0.972 & 0.370 & 66.4 & 0.990 \\
\hline $\mathrm{DH}_{\mathrm{L}} \mathrm{K}_{1}$ & 2.82 & 0.899 & 0.12 & 0.64 & 0.931 & 3.804 & 0.990 & 0.361 & 87.5 & 0.992 \\
\hline $\mathrm{DH}_{\mathrm{L}} \mathrm{K}_{2}$ & 2.96 & 0.922 & 0.13 & 1.40 & 0.96 & 3.561 & 0.975 & 0.386 & 112.7 & 0.988 \\
\hline $\mathrm{DH}_{\mathrm{L}} \mathrm{K}_{3}$ & 3.17 & 0.928 & 0.19 & 8.07 & 0.976 & 3.082 & 0.965 & 0.370 & 137.4 & 0.988 \\
\hline $\mathrm{DH}_{\mathrm{L}} \mathrm{K}_{4}$ & 3.31 & 0.929 & 0.21 & 11.16 & 0.974 & 3.052 & 0.963 & 0.391 & 154.7 & 0.984 \\
\hline $\mathrm{DH}_{\mathrm{H}} \mathrm{K}_{0}$ & 3.14 & 0.932 & 0.22 & 6.98 & 0.944 & 3.042 & 0.921 & 0.480 & 184.9 & 0.941 \\
\hline $\mathrm{DH}_{\mathrm{H}} \mathrm{K}_{1}$ & 3.69 & 0.906 & 0.26 & 19.29 & 0.958 & 2.973 & 0.930 & 0.494 & 203.3 & 0.943 \\
\hline $\mathrm{DH}_{\mathrm{H}} \mathrm{K}_{2}$ & 4.12 & 0.939 & 0.32 & 34.22 & 0.974 & 2.393 & 0.959 & 0.502 & 345.3 & 0.965 \\
\hline $\mathrm{DH}_{\mathrm{H}} \mathrm{K}_{3}$ & 4.27 & 0.933 & 0.36 & 44.96 & 0.968 & 2.454 & 0.974 & 0.731 & 354.0 & 0.919 \\
\hline $\mathrm{DH}_{\mathrm{H}} \mathrm{K}_{4}$ & 4.63 & 0.951 & 0.37 & 55.66 & 0.958 & 2.475 & 0.980 & 0.924 & 356.8 & 0.928 \\
\hline
\end{tabular}
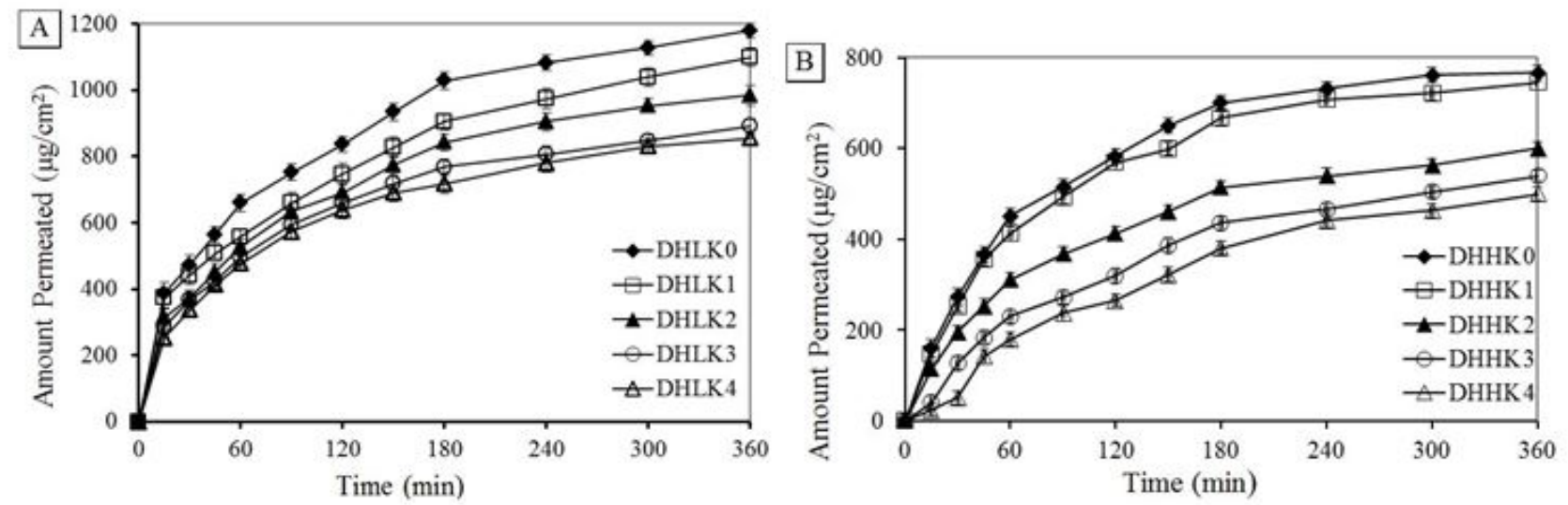

Fig. 6: (A) Ophthalmic drug permeation profile of films with $H P M C_{L}$ and (B) $H P M C_{H}$ matrix. HPMC ${ }_{H}$ has shown comparatively delayed permeation than $\mathrm{HPMC}_{\mathrm{L}}$ matrix and the function of kaolin presence also sustained the permeation in all the matrices 

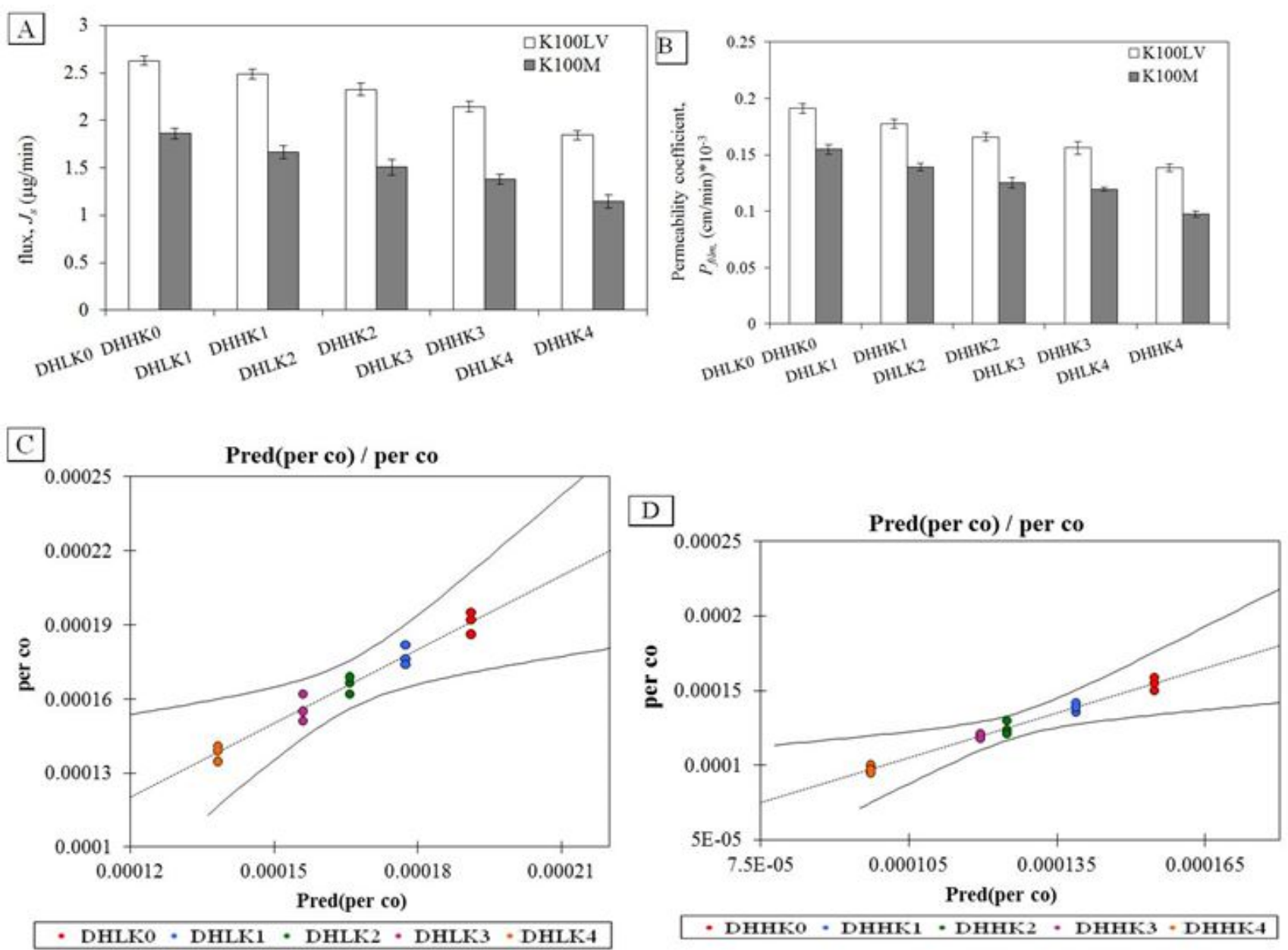

Fig. 7: (A) Effect of kaolin content and the polymer matrices $\left(H P M C_{L}\right.$ and $\left.H_{P M C}\right)$ on the flux $\left(J_{s}\right)$; $(B)$ Permeability coefficient $\left(\mathrm{P}_{\text {film }}\right)$; (C) Means chart of observed vs. predicted permeation coefficient of $\mathrm{HPMC}_{\mathrm{L}}$ and (D) $\mathrm{HPMC}_{\mathrm{H}}$

TABLE 3: DUNNETT TWO-SIDED ANALYSIS OF THE PERMEATION COEFFICIENT DIFFERENCE OF THE TWO CONTROL CATEGORIES OF DH $\mathrm{K}_{0}$ AND $\mathrm{DH}_{\mathrm{M}} \mathrm{K}_{0}$ WITH THE OTHER FILMS PAIR WISE WITH A CONFIDENCE INTERVAL OF $95 \%$

\begin{tabular}{lcccccc}
\hline Contrast & Difference *10 & $\begin{array}{c}\text { Standardized } \\
\text { difference }\end{array}$ & $\begin{array}{c}\text { Critical } \\
\text { value }\end{array}$ & $\begin{array}{c}\text { Critical difference } \\
* 10^{5}\end{array}$ & Pr>Diff & Significant \\
\hline $\mathrm{DH}_{\mathrm{L}} \mathrm{K}_{0}$ vs. $\mathrm{DH}_{\mathrm{L}} \mathrm{K}_{1}$ & 1.366 & 3.935 & 2.891 & 1.004 & $<0.0001$ & yes \\
$\mathrm{DH}_{\mathrm{L}} \mathrm{K}_{0}$ vs. $\mathrm{DH}_{\mathrm{L}} \mathrm{K}_{2}$ & 2.526 & 7.275 & 2.891 & 1.004 & $<0.0001$ & yes \\
$\mathrm{DH}_{\mathrm{L}} \mathrm{K}_{0}$ vs. $\mathrm{DH}_{\mathrm{L}} \mathrm{K}_{3}$ & 3.506 & 10.099 & 2.891 & 1.004 & 0.0001 & yes \\
$\mathrm{DH}_{\mathrm{L}} \mathrm{K}_{0}$ vs. $\mathrm{DH}_{\mathrm{L}} \mathrm{K}_{4}$ & 5.281 & 15.21 & 2.891 & 1.004 & 0.009 & yes \\
$\mathrm{DH}_{\mathrm{H}} \mathrm{K}_{0}$ vs. $\mathrm{DH}_{\mathrm{H}} \mathrm{K}_{1}$ & 1.59 & 5.592 & 2.891 & 0.822 & $<0.0001$ & yes \\
$\mathrm{DH}_{\mathrm{H}} \mathrm{K}_{0}$ vs. $\mathrm{DH}_{\mathrm{H}} \mathrm{K}_{2}$ & 2.981 & 10.483 & 2.891 & 0.822 & $<0.0001$ & yes \\
$\mathrm{DH}_{\mathrm{H}} \mathrm{K}_{0}$ vs. $\mathrm{DH}_{\mathrm{H}} \mathrm{K}_{3}$ & 3.515 & 12.361 & 2.891 & 0.822 & $<0.0001$ & yes \\
$\mathrm{DH}_{\mathrm{H}} \mathrm{K}_{0}$ vs. $\mathrm{DH}_{\mathrm{H}} \mathrm{K}_{4}$ & 5.735 & 20.166 & 2.891 & 0.822 & 0.001 & yes \\
\hline
\end{tabular}

$\mathrm{DH}_{\mathrm{H}} \mathrm{K}_{0} v s . \mathrm{DH}_{\mathrm{H}} \mathrm{K}_{2}, \mathrm{DH}_{\mathrm{H}} \mathrm{K}_{0}$ vs. $\mathrm{DH}_{\mathrm{H}} \mathrm{K}_{3}$ and $\mathrm{DH}_{\mathrm{H}} \mathrm{K}_{0}$ vs. $\mathrm{DH}_{\mathrm{H}} \mathrm{K}_{4}$. The limit of permeation coefficient prediction has been represented in mean chart of observed $v s$. predicted permeation coefficient of $\mathrm{HPMC}_{\mathrm{L}}$ and $\mathrm{HPMC}_{\mathrm{H}}$ films fig. 7C and fig. 7D. $\mathrm{P}_{\text {film }}$ and $\mathrm{J}_{\mathrm{s}}$ value of similar type of film formulation can be predicted at particular intermediate kaolin content in film from these column charts. The decreased flux with increasing kaolin content for $\mathrm{HPMC}_{\mathrm{L}}$ and $\mathrm{HPMC}_{\mathrm{H}}$ film was as $2.629-1.844$ and 1.862-1.145 respectively. Fig. 8A and fig. $8 \mathrm{~B}$ represents the relationship between amount of drug release and the amount permeated through the cornea from the films. Regression equation of release vs. permeation has already been presented in Table 2 and $\mathrm{r}^{2}$ values are found as 0.952-0.982 of $\mathrm{HPMC}_{\mathrm{L}}$ and 0.947-0.958 of $\mathrm{HPMC}_{\mathrm{H}}$ films. 

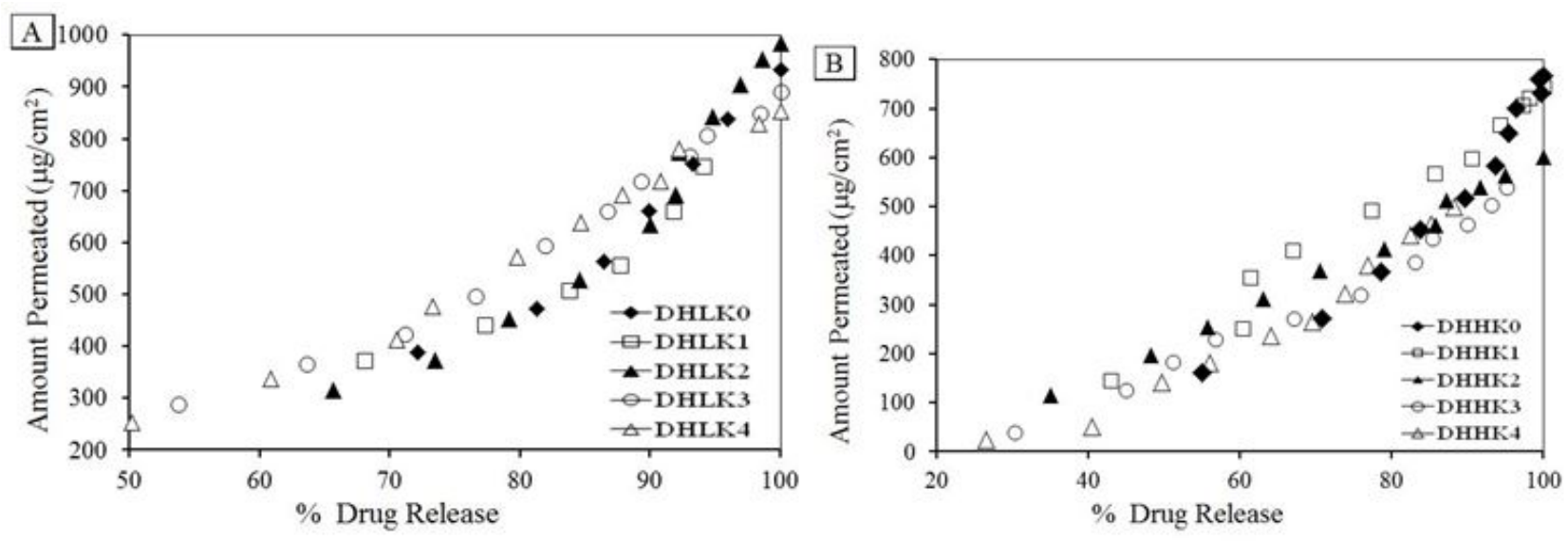

Fig. 8: Relationship between drug release and corneal permeation of $H P M C_{L}$ and $H P M C_{H}$ films. All profiles are linearly correlated ( $r^{2}$ values are $0.952-0.982$ and $0.947-0.958$ respectively)

Corneal permeation of DXA prolonged from $\mathrm{HPMC}_{\mathrm{H}}$ matrix film than $\mathrm{HPMC}_{\mathrm{L}}$ matrix film because of reduced effective molecular diffusion due to higher viscosity. Based on the pair wise comparison, a significant difference in corneal permeation was observed between the film without kaolin and with kaolin content. This significant difference established the effect of kaolin on corneal permeation. Corresponding increased $t_{50}$ of permeation with increased kaolin content in the film can be recognized as the efficiency of prolonging drug delivery. Significant difference between permeation coefficient of the film with different kaolin content was confirmed by ANOVA. A good relationship between corneal permeation and release could ascertain the batch to batch consistency in biological performance and consequently an indication in the physiological performance of the films. Drug release study may serve as a surrogate for biological tissue permeation performance. Any change in the film formulation could be justified without the need of supplementary studies with biological tissues.

The phases of eye before and after inflammation study showed in fig. 9. The normal eye before carrageenan induction has shown in fig. 9A-fig. 9C showed the sign of inflammation as conjunctival redness and swelling were gradually developed in the rabbit eye after $30 \mathrm{~min}$ and $1 \mathrm{~h}$ of injection respectively. Fig. 9D showed the rabbit eye after some time application of film in the cul-de-sac. Fig. 9E showed the reduced inflammation after $3 \mathrm{~h}$ of application of $\mathrm{DH}_{\mathrm{H}} \mathrm{K}_{4}$ film in the cul-de-sac. Inflammation after $3 \mathrm{~h}$ without applying film could be compared (F).

Inflammation has been reduced because of diffusion of DXA into the corneal tissue. The film was not found to have a tendency to move across the surface of the eye due to the presence of mucoadhesive polymer
(HPMC), thus resulting in minimizing ophthalmic irritation and burning sensations. Disappearance of redness and tearing of the eye and complete relief of inflammation was noticed. The residence time of the film has been prolonged by mucoadhesion and this could be beneficial in improving patient compliance by reducing the treatment to a single application.

To understand the fitting and stable configuration of drug-carrier interaction, in silico docking study has been used. The PDB structure form of DXA, kaolin and HPMC are shown in fig. 10 respectively. Fig. 10 $\mathrm{D}$ and fig. 10E showed the docking configuration of DXA-kaolin complex, DXA-kaolin-HPMC complex, DXA-HPMC complex and (DXA-HPMC) kaolin complex respectively. The different complexes formed are complex-I DXA-Kaolin, complex-II (DXA-kaolin) HPMC, showed change in binding affinities/energies are $-3.30 \mathrm{kcal} / \mathrm{mol},-2.33 \mathrm{kcal} / \mathrm{mol}$ respectively.

The DXA formed complex through hydrogen bond with various small molecules such as HPMC and kaolin. The higher negative binding energy values indicate stable interactions than that of lower negative values, which indicate destabilizing interactions. It has been clearly showed that the complex-II possess more stable based on lower binding energy. The DXA side chain O-H and carbonyl groups $(\mathrm{C}=\mathrm{O})$ formed two hydrogen bond with the $\mathrm{OH}$ groups of $\mathrm{Al}-\mathrm{OH}$ of kaolin respectively in complex-I, however the $\mathrm{OH}$ group of DXA in complexII formed hydrogen bond with that of $\mathrm{OH}$ group of HPMC. These polar group interaction play a major role in all the complexes and responsible for key binding of the drug with the complexion agents. This interaction has also been supported by the FT-IR result, where the shifting of carbonyl group of DXA and - OH of Al$\mathrm{OH}$ of kaolin has been observed. This stable complex 

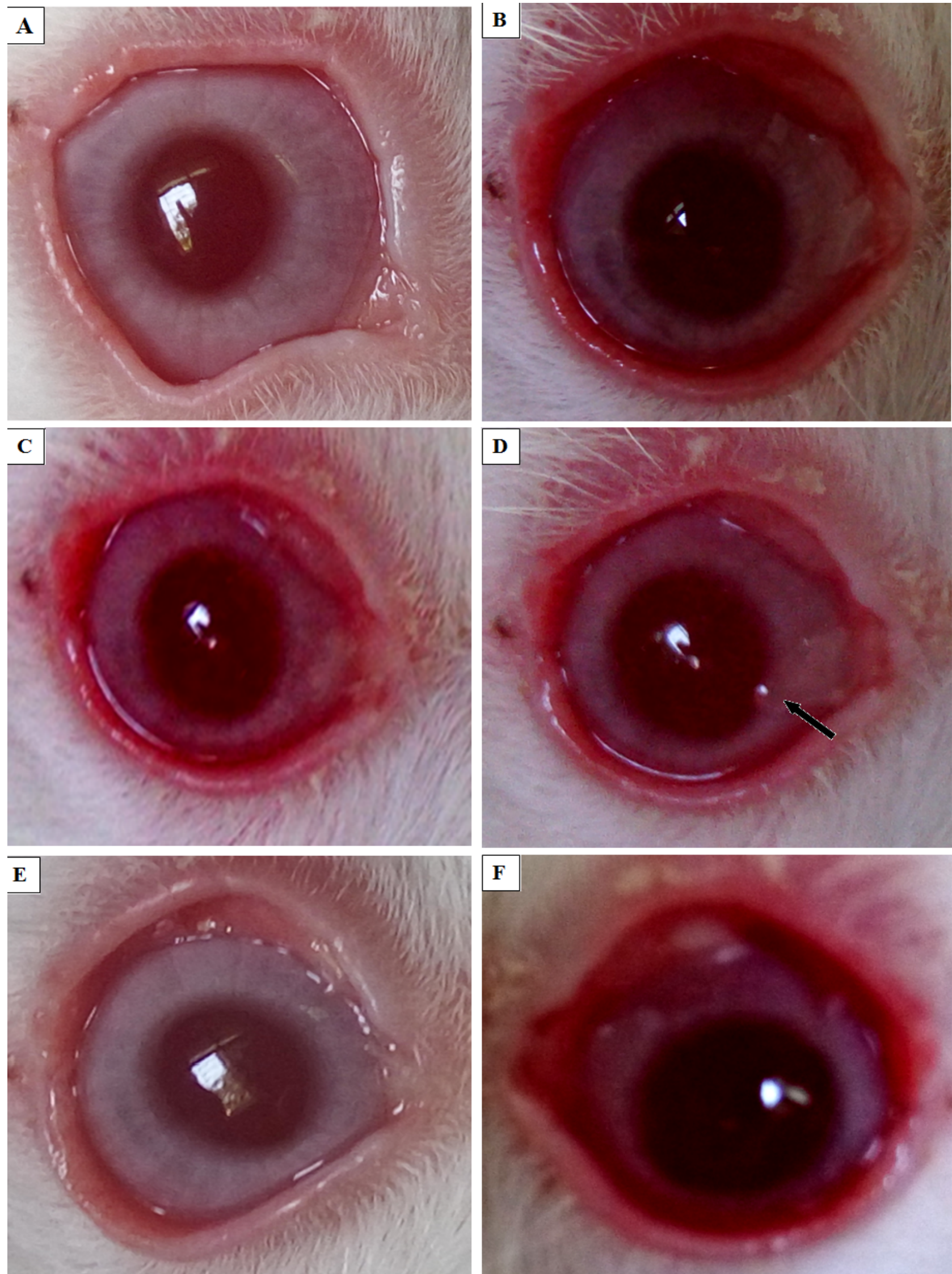

Fig. 9: (A) Normal rabbit eye before carrageenan injection; (B) Conjunctival swelling and redness developed after 30 min; (C) After $1 \mathrm{~h}$; DXA film $\left(\mathrm{DH}_{\mathrm{H}} \mathrm{K}_{4}\right)$ was applied to the cul-de-sac; (D) Few minutes after partial hydration of the film together with reduced inflammation; (E) After $3 \mathrm{~h}$ of film application disappearance of redness and tearing of the eye and complete relief of inflammation; (F) Inflammation after $3 \mathrm{~h}$ without applying film 


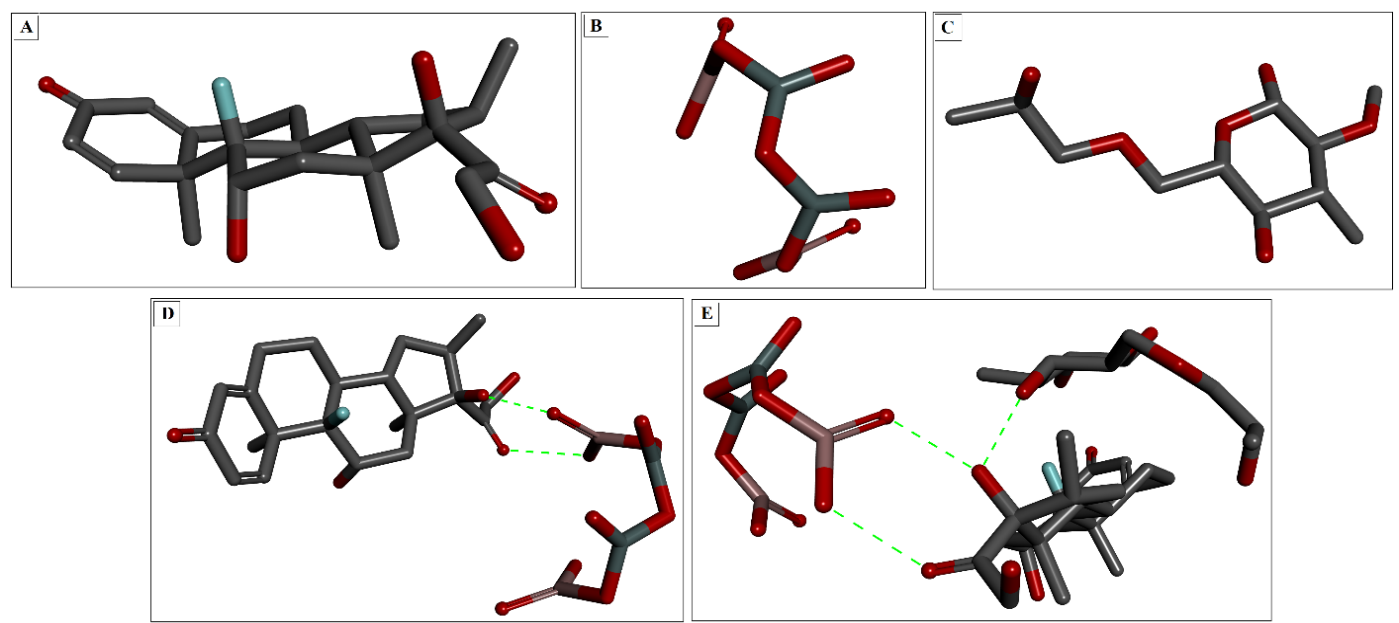

Fig. 10: (A) PDB structure of DXA; (B) PDB structure of kaolin; (C) PDB structure of HPMC; (D) Docked structure of DXA-kaolin; (E) Docked structure of DXA-kaolin-HPMC

facilitated the sustained ophthalmic delivery of DXA and prolonged anti-inflammatory activity.

\section{Acknowledgments:}

The authors are indebted to Dr. Monoj Ranjan Nayak, President, Siksha 'O' Anusandhan (Deemed to be University) for supporting financially and laboratory facility. We are also acknowledging thankfulness to receive DXA as gift sample from Lupin Research Park, Pune, India. Especially we wish to show gratitude towards Dr. Tapobrata Som, Professor, Institute of Physics, Bhubaneswar for providing XRD instrument facility.

\section{Conflict of interests:}

The authors declare no conflicts of interest.

\section{REFERENCES}

1. Suresh PK, Dewangan D. Ophthalmic delivery system for dexamethasone: An Overview. Int $\mathrm{J}$ Innov Pharm Res 2011;2(4):161-5.

2. Miniauskiene G, Jasinskas V. Association of metabolic syndrome with abnormalities of bulbar conjunctival vessels. Medicina 2008;44(2):100-9.

3. Saraiya NV, Goldstein DA. Dexamethasone for ocular inflammation. Expert Opin Pharmacother 2011;12(7):1127-31.

4. Zignani M, Einmahl S, Baeyens V, Varesio E, Veuthey JL, Anderson $\mathrm{J}$, et al. Poly (orthoester) designed for combined ocular delivery of dexamethasone sodium phosphate and 5-fluorouracil: sub conjunctival tolerance and in vitro release. Eur J Pharm Biopharm 2000;50:251-5.

5. Loftsson T, Frioriksdottir H, Thorisdottir S, Stefansson E. The effect of hydroxypropyl methylcellulose on the release of dexamethasone from aqueous 2 -hydroxypropyl- $\beta$-cyclodextrin formulations. Int J Pharm 1994;104:181-4.

6. Maurice DM, Mishima S. Ocular pharmacokinetics. Pharmacol Eye 1984:19-116.

7. Weijtens O, Schoemaker RC, Romijn FP, Cohen AF, Lentjes EG, van Meurs JC. Intraocular penetration and systemic absorption after topical application of dexamethasone disodium phosphate. Ophthalmology 2002;109(10):1887-91.

8. Sangfai T, Dong F, Tantishaiyakul V, Jandt KD, Lüdecke $\mathrm{C}$, Boonrat $\mathrm{O}$, et al. Layer-by-layer gelatin/chitosan polyelectrolyte coated nanoparticles on $\mathrm{Ti}$ implants for prevention of implant-associated infections. Express Polymer Lett 2017;11(1):73-82.

9. Qi H, Chen W, Huang C, Li L, Chen C, Li W, et al. Development of a poloxamer analogs/carbopol-based in situ gelling and mucoadhesive ophthalmic delivery system for puerarin. Int $\mathrm{J}$ Pharm 2007;337(1):178-87.

10. Kaur IP, Garg A, Singla AK, Aggarwal D. Vesicular systems in ocular drug delivery: an overview. Int J Pharm 2004;269(1):1-4.

11. Sipai AM, Yadav V, Mamatha Y, Prasanth VV. Liposomes: an overview. J Pharm Sci Innov 2012;1:13-21.

12. Das D, Pal S. Modified biopolymer-dextrin based crosslinked hydrogel: application in controlled drug delivery. RSC Adv 2015;5:25014-50.

13. Ghadiri M, Chrzanowski W, Rohanizadeh R. Biomedical applications of cationic clay minerals. RSC Adv 2015;5(37):29467-81.

14. Carretero MI. Clay minerals and their beneficial effects upon human health: A review. Appl Clay Sci 2002;21(3-4):155-63.

15. Swain K, Pattnaik S, Sahu SC, Mallick S. Feasibility assessment of ondansetron hydrochloride transdermal systems: physicochemical characterization and in vitro permeation studies. Lat Am J Pharm 2009;28(5):706-14.

16. Mohapatra R, Senapati S, Sahoo C, Mallick S. Transcorneal permeation of diclofenac as a function of temperature from film formulation in presence of triethanolamine and benzalkonium chloride. Colloids Surf B Biointerfaces 2014;123:170-80.

17. Nanda A, Sahoo RN, Pramanik A, Mohapatra R, Pradhan SK, Thirumurugan A, et al. Drug-in-mucoadhesive type film for ocular anti-inflammatory potential of amlodipine: Effect of sulphobutyl-ether-beta-cyclodextrin on permeation and molecular docking characterization. Colloids Surf B Biointerfaces 2018;172:555-64.

18. Saettone MF, Salminenb L. Ocular inserts for topical delivery. Adv Drug Deliv Rev 1995;16:95-106.

19. Gupta GD, Gaud RS. Antiinflammatory activity of tenoxicam gel on carrageenan-induced paw oedema in rats. Indian $\mathrm{J}$ Pharm Sci 2006;68(3):158-63.

20. Kato M, Hagiwara $\mathrm{Y}$, Oda $\mathrm{T}$, Imamura-Takai M, Aono $\mathrm{H}$, Nakamura M. Beneficial pharmacological effects of selective 
glucocorticoid receptor agonist in external eye diseases. J Ocular Pharmacol Ther 2011;27(4):353-60.

21. Van Olphen H. An introduction to clay colloid chemistry. Soil Sci 1964;97(4):290.

22. Pattnaik S, Swain K, Bindhani A, Mallick S. Influence of chemical permeation enhancers on transdermal permeation of alfuzosin: an investigation using response surface modeling. Drug Dev Ind Pharm 2011;37(4):465-74.

23. Swain K, Pattnaik S, Sahu SC, Patnaik KK, Mallick S. Drug in adhesive type transdermal matrix systems of ondansetron hydrochloride: optimization of permeation pattern using response surface methodology. J Drug Target 2010;18(2):106-14.

24. Cao N, Fu Y, He J. Preparation and physical properties of soy protein isolate and gelatin composite films. Food Hydrocolloid 2007;21(7):1153-62.

25. Echeverría I, Eisenberg P, Mauri AN. Nanocomposites films based on soy proteins and montmorillonite processed by casting. J Membrane Sci 2014;449:15-26.

26. Lin J, Wu H, Wang Y, Lin J, Chen Q, Zhu X. Preparation and ocular pharmacokinetics of hyaluronan acid-modified mucoadhesive liposomes. Drug Deliv 2016;23(4):1144-51.

27. Pattnaik S, Swain K, Rao JV, Varun T, Mallick S. Temperature influencing permeation pattern of alfuzosin: An investigation using DoE. Medicina 2015;51(4):253-61.

28. Mohapatra R, Mallick S, Nanda A, Sahoo RN, Pramanik A, Bose A, et al. Analysis of steady state and non-steady state corneal permeation of diclofenac. RSC advances 2016;6(38):31976-87.

29. Shukr M. Formulation, in vitro and in vivo evaluation of lidocaine $\mathrm{HCl}$ ocular inserts for topical ocular anesthesia. Arch Pharm Res 2014;37(7):882-9.

30. Soiberman U, Kambhampati SP, Wu T, Mishra MK, Oh $\mathrm{Y}$, Sharma R, et al. Subconjunctival injectable dendrimerdexamethasone gel for the treatment of corneal inflammation. Biomaterial 2017; 125:38-53.

31. Mallick S, Gupta BK, Ghosal SK. Development and characterization of release profile of nifedipine as an effective controlled release system. J Sci Ind Res 1999;58:1010-6.

32. Mallick S, Sahu A, Pal K. Dissolution behaviour of nalidixic acid solid dispersions using water soluble dispersion carriers. Acta Pol Pharm 2004;61(1):21-30.

33. Korsmeyer RW, Peppas NA. Effect of the morphology of hydrophilic polymeric matrices on the diffusion and release of water soluble drugs. J Membrane Sci 1981;9(3):211-27.

34. Mohapatra R, Mallick S. Transient and steady state characterization of permeation kinetics of diclofenac through ocular tissue. Asian J Chem 2016;28(5):1149.

35. One-way ANOVA and multiple comparisons in Excel tutorial, Addinsoft SARL, XLSTAT; 2017.

36. Morris GM, Huey R, Lindstrom W, Sanner MF, Belew RK, Goodsell DS, et al. AutoDock4 and AutoDockTools4: Automated docking with selective receptor flexibility. J Comput Chem 2009;30(16):2785-91.

37. Maharana J, Patra MC, De BC, Sahoo BR, Behera BK, De S, et al. Structural insights into the MDP binding and CARD-CARD interaction in zebrafish (Danio rerio) NOD2: a molecular dynamics approach. J Mol Recognit 2014;27(5):260-75.

38. Veurink M, Westermaier Y, Gurny R, Scapozza L. Breaking the aggregation of the monoclonal antibody bevacizumab $\left(\right.$ Avastin $^{\mathbb{R}}$ ) by dexamethasone phosphate: insights from molecular modelling and asymmetrical flow field-flow fractionation. Pharm Res 2013;30(4):1176-87.

39. Morris GM, Goodsell DS, Halliday RS, Huey R, Hart WE, Belew RK, et al. Automated docking using a Lamarckian genetic algorithm and an empirical binding free energy function. J Comput Chem 1998;19(14):1639-62.

40. Shinde RS, Mas VH, Patil MK. Antiinflammatory Activity of Triazine Thiazolidinone Derivatives: Molecular Docking and Pharmacophore Modeling. Indian J Pharm Sci 2019;81(5):851-8.

41. Acharya M, Mishra S, Sahoo RN, Mallick S. Infrared spectroscopy for analysis of co-processed ibuprofen and magnesium trisilicate at milling and freeze drying. Acta Chim Slov 2017;64(1):45-54.

42. Hassan N, Latif S, Afzal H, Abbas N, Naheed S, Khokar R, et $a l$. Taste masking of levofloxacin by microparticulate system using emulsion solvent evaporation technique. Indian J Pharm Sci 2019;81(5):843-50.

43. Doile MM, Fortunato AK, Schmücker IC, Schucko SK, Silva MA, Rodrigues PO. Physicochemical properties and dissolution studies of dexamethasone acetate- $\beta$-cyclodextrin inclusion complexes produced by different methods. AAPS Pharm Sci Tech 2008;9(1):314-21.

44. Saikia BJ, Parthasarathy G. Fourier transform infrared spectroscopic characterization of kaolinite from Assam and Meghalaya, Northeastern India. J Mod Phys 2010;1(4):206-10.

45. Kristó J, Frost RL, Felinger A, Mink J. FTIR spectroscopic study of intercalated kaolinite. J Mol Structure 1997;410:119-22.

46. Panda B, Subhadarsini R, Mallick S. Biointerfacial phenomena of amlodipine buccomucosal tablets of HPMC matrix system containing polyacrylate polymer/ $\beta$-cyclodextrin: correlation of swelling and drug delivery performance. Expert Opin Drug Deliv 2016;13(5):633-43.

47. Krstić M, Ražić S, Đekić Lj DV, Momčilović M, Vasiljević D, Ibrić S. Application of a mixture experimental design in the optimization of the formulation of solid self-emulsifying drug delivery systems containing carbamazepine. Lat Am J Pharm 2015;34(5):885-94.

48. Mallick S, Pattnaik S, Swain K, De PK, Saha A, Ghoshal $\mathrm{G}$, et al. Formation of physically stable amorphous phase of ibuprofen by solid state milling with kaolin. Eur J Pharm Biopharm 2008;68(2):346-51.

49. Krstic M, Djuris J, Petrovic O, Lazarevic N, Cvijic S, Ibric S. Application of the melt granulation technique in development of lipid matrix tablets with immediate release of carbamazepine. J Drug Deliv Sci Technol 2017;39:467-74.

50. Panda B, Parihar AS, Mallick S. Effect of plasticizer on drug crystallinity of hydroxypropyl methylcellulose matrix film. Int J Biol Macromol 2014;67:295-302.

51. Rekik SB, Bouaziz J, Deratani A, Beklouti S. Study of ceramic membrane from naturally occurring-kaolin clays for microfiltration applications. Period Polytech Chem Eng 2017;61(3):206-15.

52. Pruett RJ, Murray HH. Mineralogical and geochemical controls that source rocks impose on sedimentary kaolins. Clay Miner Soc Spec Pub 1990:149-70.

53. Wiewiora A, Brindley GW. Potassium acetate intercalation in kaolinite and its removal; effect of material characteristics. Proc Int Clay Con Tokyo 1969;1:723-9.

54. Sahoo RN, Nanda A, Pramanik A, Nandi S, Swain R, Pradhan SK, et al. Interactions between Ibuprofen and Silicified-MCC: characterization, drug release and modeling approaches. Acta Chim Slov 2019;66(4):923-33.

55. Rausell-Colom J, Serratosa J. Chemistry of clays and clay minerals. In; Newman, A C D, Ed.; Mineralogical Society Monograph. New York: Wiley Interscience; 1987.

56. Colombo P, Bettini R, Massimo G, Catellani PL, Santi P, Peppas NA. Drug diffusion front movement is important in drug release control from swellable matrix tablets. J Pharm Sci 1995;84(8):991-7. 